\title{
O IQA DO IGARAPÉ DO COLOMBO QUE ABASTECE O PROJETO DE ASSENTAMENTO SÃO FRANCISCO, CANUTAMA/AM
}

Ísis Ribeiro do Nascimento - isis.ufam@gmail.com

Universidade Federal do Amazonas

Luciano Ferreira Paes - ferreirapaes@ hotmail.com

Universidade Federal do Amazonas

Aryanne Resende de Melo Moura - aryanne_mm@hotmail.com

Universidade Federal do Amazonas

Altemar Lopes Pedreira Junior - merklein3@ hotmail.com

Universidade Federal do Amazonas

André Moreira Bordinhon - ambordinhon@gmail.com

Universidade Federal do Amazonas

Keith Soares Valente - Keith.ufam@gmail.com

Universidade Federal do Amazonas 


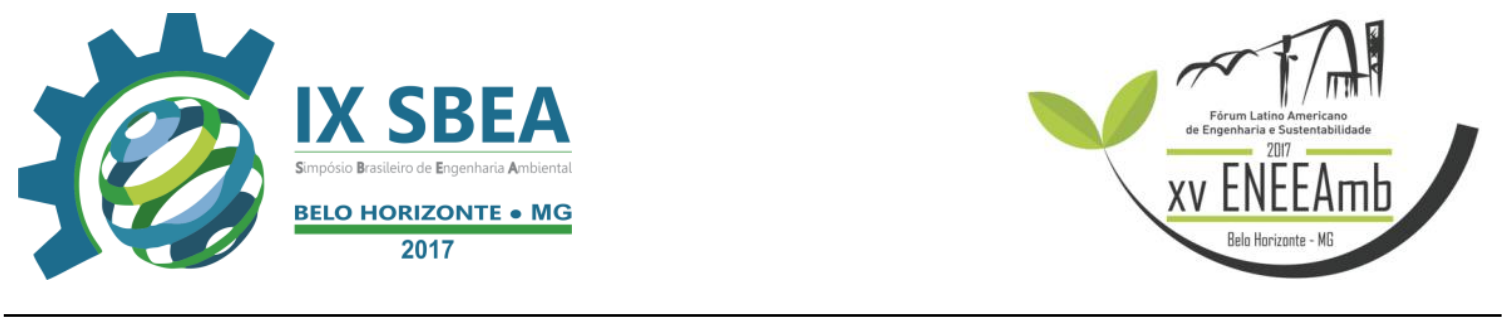

\section{RESUMO}

O Índice de Qualidade da Água (IQA) é uma ferramenta que leva as pessoas leigas uma resposta de fácil interpretação sobre o grau de poluição de um corpo hídrico, este trabalho está buscando levar a resposta sobre a qualidade da água do Igarapé do Colombo utilizada para o consumo humano no Projeto de Assentamento São Francisco, Canutama/AM, afim de que o IQA sirva como um dos indicadores da saúde da população local que dela faz uso, sendo que parte das doenças encontradas em localidades afastadas dos centros urbanos tem alguma relação com a água e daí gerando uma informação precisa quanto a qualidade da água às pessoas residentes nesse Projeto de Assentamento.

Palavras-chave: SBEA, ENEEAmb, Fórum Latino Americano, Assentamento rural, Canutama, IQA, saneamento rural

\section{INTRODUÇÃO/OBJETIVO}

A intensa forma como o homem vem usando o ambiente nas últimas décadas, nos leva a pensar até quando o ecossistema manterá sua capacidade de suporte, pois a degradação do meio ambiente traz consequências duras ao equilíbrio do planeta se feito de forma desordenada e acelerada, afetando a condição de vida das pessoas deixando-as expostas a riscos de saúde,

São evidentes os sinais de deterioração do ambiente na escala planetária. A destruição de ecossistemas, a contaminação crescente da atmosfera, solo e água, bem como o aquecimento global são exemplos dos impactos das atividades humanas sobre $o$ ambiente (BARCELLOS \& QUITÉRIO, 2006, p. 171).

A degradação dos recursos hídricos e as formas exploratórias que sofrem, nos leva a pensar que medidas preventivas e mitigadoras devem ser tomadas senão para evitar mas para frear a crescente perda desses recursos, seja por poluição, seja pelo crescente aumento de sua demanda tanto para o crescimento econômico quanto social utilizando a água em seus usos múltiplos, 


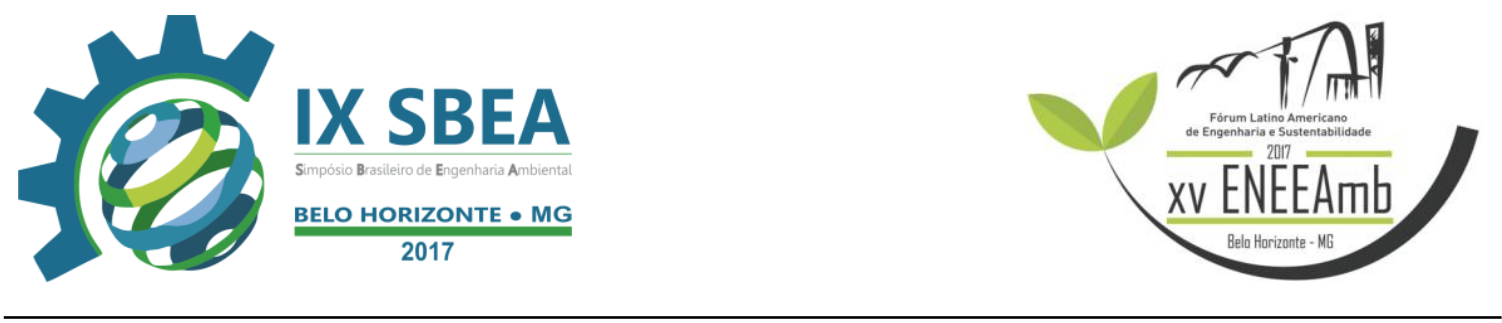

Os usos múltiplos da água, as permanentes necessidades para atendimento ao crescimento populacional, às demandas industriais e agrícolas têm gerado permanente pressão sobre os recursos hídricos superficiais e subterrâneos (SILVA et. al, 2012, p. 17).

Há, portanto, a necessidade em se fazer o cruzamento de informações entre o ambiente, o saneamento básico e as doenças de veiculação hídrica para identificar as situações que expõem populações rurais a contrair doenças de veiculação hídrica por conta da qualidade da água que utilizam para abastecimento. Por isso índices e indicadores são parâmetros de interesse público que dão uma resposta simples e rápida.

O Índice de Qualidade da Água (IQA) consolidou-se em nível internacional a partir de um estudo realizado pela National Sanitation Foundation (NSF) dos Estados Unidos e sua utilização é grande devido a sua aplicabilidade em transmitir informações sobre o grau de poluição de mananciais utilizados pelos seres humanos (BENNETTI \& BIDONE, 2001).

O índice consiste em sumarizar em um único valor, as nove variáveis utilizadas em seu cálculo, dando aos mesmos pesos relativos e condição com que se apresenta cada parâmetro segundo uma escala de valores "rating". Estes parâmetros são: oxigênio dissolvido, coliformes termotolerantes, potencial hidrogeniônico, demanda bioquímica de oxigênio, temperatura, fósforo total, turbidez e resíduo total, tendo como principal determinante o seu uso para abastecimento humano (CETESB, 2015). O IQA é o produtório ponderado dos nove parâmetros com seus respectivos pesos e a fórmula para o seu cálculo é:

$$
\mathrm{IQA}=\prod_{\mathrm{i}=1}^{\mathrm{n}} \mathrm{q}_{\mathrm{i}}^{\mathrm{w}_{\mathrm{i}}}
$$

Fonte: CETESB, 2012

Onde,

IQA = índice de qualidade de água, variando de 0 a 100; 


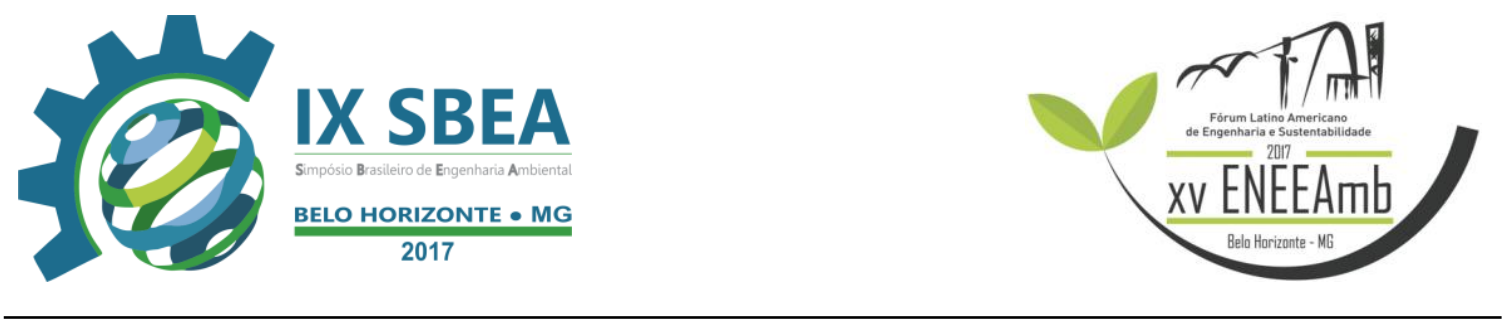

qi = qualidade do i-ésimo parâmetro, um número entre 0 e 100, obtido por meio da curva média de variação de qualidade em função de sua concentração ou medida;

wi $=$ peso correspondente ao i-ésimo parâmetro um número entre 0 e 1 , em função de sua importância para a conformação global de qualidade.

E sabendo da forte relação entre a qualidade da água para consumo e a saúde da população, que esta pesquisa foi pensada, pois o IQA vem dá resposta a contaminação causada principalmente pelo despejo de esgoto doméstico já que o meio rural tem altas incidência de contaminação pelo uso de poços rasos antigos e sem manutenção, uso direto da água de mananciais ou mesmo pela proximidade de pastagens e fossas próximas aos locais desses corpos d'água.

Segundo (HOLMES, 1996; VARIS, 1996), a contaminação da água tem origem principalmente pelos esgotos domésticos, industriais e exploração agrícola que se dá na grande maioria pelo tipo de ocupação do solo.

Geralmente a fonte da água utilizada pelas populações rurais é feita por soluções alternativas individuais onde a forma de abastecimento de água é feita para uma única família, com águas oriundas de fontes superficiais como igarapés e água das chuvas e outras vezes por poços semi-artesianos ou raso. A esse respeito verificamos que.

O tratamento da água das soluções alternativas individuais (SAIs) é realizado no meio intradomiciliar, através de fervura ou filtração, e do uso do hipoclorito de sódio $2,5 \%$ fornecido pelas Secretarias Municipais de Saúde. [...] Essas águas podem ser de poços contaminados, sobretudo quanto são poços freáticos ou cacimbas, açudes ou outros corpos d'água onde a coleta é feita pela família, podendo apresentar altos níveis de coliformes totais e/ou de $E$. coli.(BRASIL, 2015, p. 20).

Segundo a Agência Nacional de Águas, os estados amazônicos detêm mais de $80 \%$ da água doce disponível no país, enquanto áreas de alto desenvolvimento industrial e alta densidade populacional, como o Estado de São Paulo, possuem a água como fator 


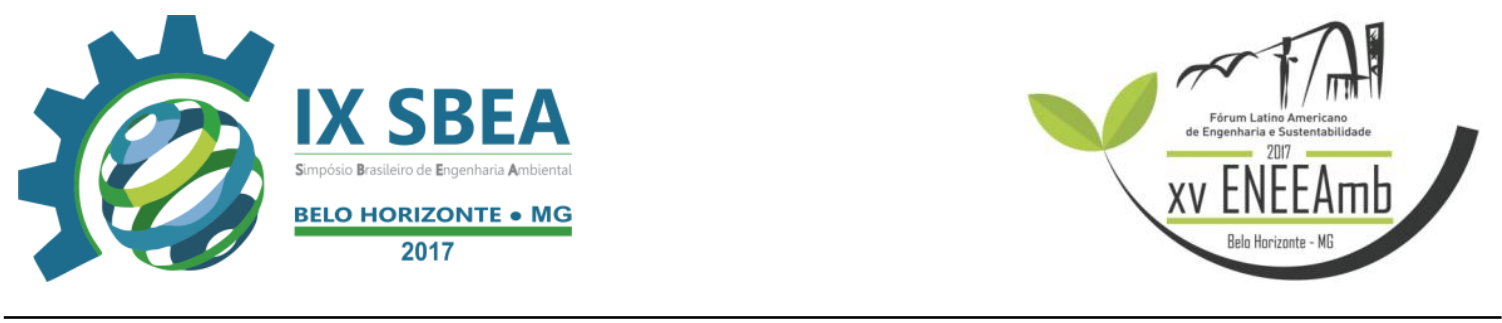

limitante (ANA, 2012). No entanto, na região Norte do Brasil, os dados de domicílios sem os serviços de saneamento essenciais (abastecimento de água, coleta de lixo e esgotamento sanitário), corresponde a 37,7\%, ficando muito acima da média nacional que é de 15\% (BRASIL, 2015), assim “populações em ambientes sem fornecimento de água ou sem demais componentes do saneamento amplia-se pela soma das populações que recebem água sem qualquer tipo de tratamento, de diferentes formas de abastecimento".

Pessoas que utilizam água para beber sem tratamento acabam ficando expostas/vulneráveis sendo que o tratamento da água para torná-la potável é o que garante sua qualidade e diminui os riscos à saúde: "a falta de implantação de políticas de saneamento, especialmente relacionados ao abastecimento de água, podem circunscrever uma população vulnerável, privada de benefícios sociais previstos na Lei do Saneamento que determina que a água deve ser um serviço exercido em caráter universal” (BRASIL, 2007).

Diante do exposto, este projeto de pesquisa teve como área de campo o Projeto de Assentamento São Francisco, criado pela Resolução 019/1993 em regime de regularização fundiária. Este assentamento está localizado ao sul do município de Canutama/AM, seu acesso principal se dá por meio da BR 319 através de um ramal de terra com $16 \mathrm{~km}$ de extensão, pela rodovia o acesso ao assentamento é feito diretamente ao estado de Rondônia e ao município de Humaitá também no Amazonas. O acesso do assentamento a sede do município de Canutama pode ser feita diretamente da comunidade por meio de voadeira que leva no mínimo 12 horas de viagem.

Com um universo de 120 a 150 famílias, que em sua grande maioria não são naturais do Amazonas, a realidade do PA São Francisco nos mostra a existência de um modelo de assentamento baseado nas políticas de ocupação da Amazônia dos anos 1970.

Neste sentido, para Cesa \& Duarte (2010) "a existência de grupos sociais que vivem em localidades com carência de serviços de saneamento ambiental acabam 


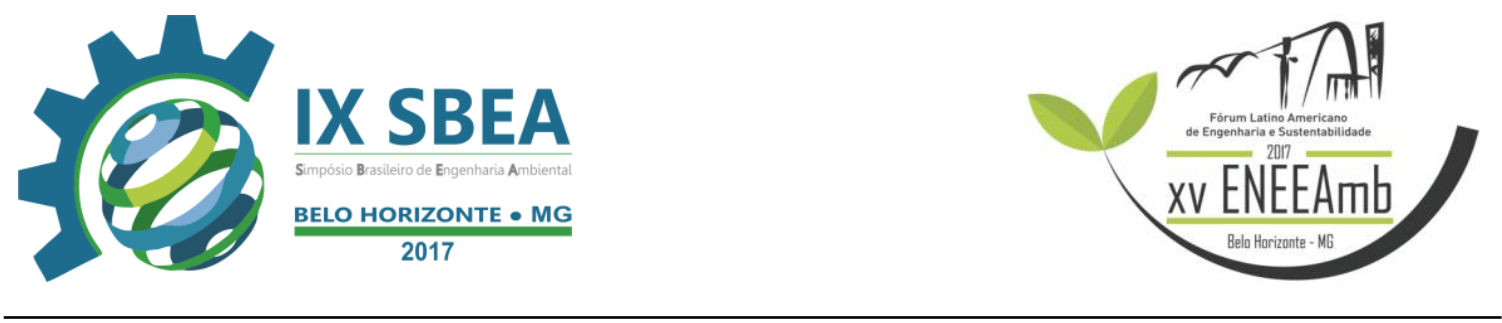

sujeitos a potencializar os efeitos adversos na saúde por meio de contaminantes locais e proliferação de vetores e outros".

"O IQA, sendo um instrumento para a verificação da qualidade das águas, é um importante instrumento para a compreensão da condição desta localidade que carece em atendimento de políticas públicas que atendam a equidade tão falada e que prevê assegurar à atual e às futuras gerações a necessária disponibilidade de água em padrões de qualidade adequados aos respectivos usos" (BRASIL, 2015).

Assim, esta pesquisa buscou verificar a qualidade higiênico-sanitária da água do Igarapé do Colombo em dois pontos distintos e fazer uma comparação temporal (período seco e chuvoso) para analisar se o IQA apresentaria diferenças significativas.

\section{METODOLOGIA}

A estudo foi realizado com uma visita prévia à campo para o dimensionamento da pesquisa e para sanar possíveis dúvidas que poderiam ocorrer durante a pesquisa in loco e assim o trabalho foi executado em dois momentos, para a realização da primeira etapa.

No primeiro momento, no mês de outubro foi feita a aplicação de questionários, depois de levantada a amostragem pelo cálculo amostral para pesquisa quantitativa de acordo com (SANTOS, 2015). Os dados obtidos pelos questionários foram tabulados e quantificados no programa Microsoft Office Excel 2016 para que ao final da pesquisa as informações neles contida fossem confrontadas com o resultado analítico obtido pelo IQA.

Em seguida, o segundo momento foi a ida à campo no mês de novembro para a coleta de água em dois pontos do Igarapé do Colombo, que corta o Projeto de Assentamento nas suas 3 estradas vicinais, de acordo com o Guia Nacional de Coleta e Preservação de Amostras (ANA, 2011).

No momento da coleta foi possível medir três parâmetros in loco sendo estes o potencial hidrogeniônico com o uso de um pHmetro portátil da marca YSI modelo 
EcoSense pH 10A e na medição de oxigênio dissolvido e temperatura foi utilizada a sonda multiparâmetro da marca YSI modelo Pro20. Os demais parâmetros foram analisados no Laboratório de Água, Petróleo e Efluentes - LAPEF - na cidade de Porto Velho/RO de acordo com (APHA, 2003).

Para o tratamento e cálculo do IQA foi utilizado o software IQA Data (Posselt, 2015) que é um software dedicado ao desenvolvimento e aplicação de diferentes índices de qualidade da água, em conjunto com o Microsoft Office Excel 2016.

O software IQAData 2015 têm suas variáveis e respectivos pesos adotados conforme (NSF, 2007) conforme abaixo:

Tabela 1 - Variáveis e respectivos pesos adotados no modelo de IQA da NSF

\begin{tabular}{|l|l|l|}
\hline Variáveis & Unidade de medida & Pesos (wi) \\
\hline Coliformes termotolerantes & $\mathrm{NMP} 100 \mathrm{~mL}^{-1}$ & 0,16 \\
\hline $\begin{array}{l}\text { Demanda Bioquímica de } \\
\text { Oxigênio }\end{array}$ & $\mathrm{mgL}^{-1}, \mathrm{O}_{2}$ & 0,11 \\
\hline Fosfato total & $\mathrm{mgL}^{-1}, \mathrm{PO}_{4}^{3-}$ & 0,10 \\
\hline Nitratos & $\mathrm{mgL}^{-1}, \mathrm{NO}_{3}{ }^{-}$ & 0,10 \\
\hline Oxigênio Dissolvido & $\%$ Saturação & 0,17 \\
\hline Potencial Hidrogeniônico & - & 0,11 \\
\hline Sólidos Totais Dissolvidos & $\mathrm{mgL}^{-1}$ & 0,07 \\
\hline Temperatura & ${ }^{\circ} \mathrm{C}$ & 0,10 \\
\hline Turbidez & $\mathrm{uT}$ ou NTU & 0,08 \\
\hline
\end{tabular}

\section{RESULTADOS E DISCUSSÃO}

Os resultados obtidos partem do confronto da percepção dos moradores quanto a água que utilizam para consumo e os testes realizados em laboratório para a resposta dos mesmos, uma vez que os mesmos relataram que água limpa e aparentemente transparente é uma água boa para beber sem precisar passar por nenhum tipo de tratamento prévio. Apresentar os dados obtidos, análise e discussão dos resultados.

Este tipo de atitude, segundo Amaral (2003) é caracterizado porque pessoas que bebem água por um longo período e não apresentam problemas de saúde evidentes, não 


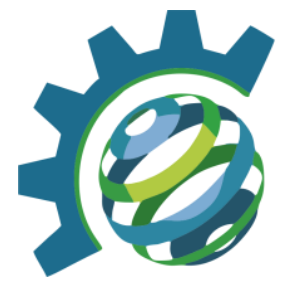

agregam juízo de valor para fazer o tratamento da água que estão utilizando para beber achando que água limpa é água pura e livre de contaminação.

Então os resultados analíticos vieram nos mostrar a real situação da água que os moradores daquele assentamento estão consumindo tanto para beber quanto para todas as suas demais necessidades. Assim, a figura 1, apresenta os resultados analíticos das amostras de água do Igarapé do Colombo com seus respectivos IQA's.

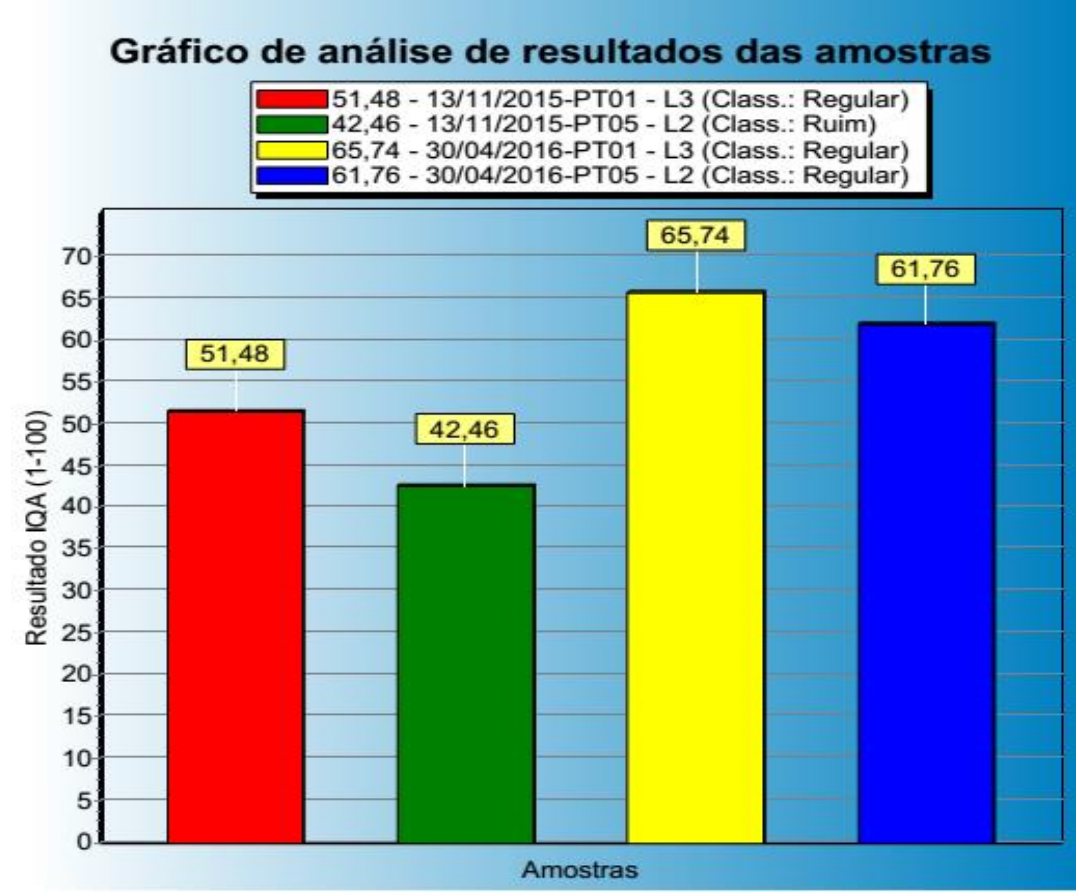

Figura 1 - IQA's dos igarapés no período seco e chuvoso

Os dois pontos de coleta do Igarapé do Colombo estão em evidência que a poluições e contaminação tendem se agravar pois o ponto 01, em vermelho (período seco) com classificação de IQA igual a 51,48 (regular) está à beira da estrada que dá acesso ao final da estrada vicinal 3, sendo um local de constante movimentação de veículos próximos ao ponto de coleta e onde está havendo uma expansão na área desmatada no entorno desse corpo hídrico para o plantio familiar e criação para subsídio. 


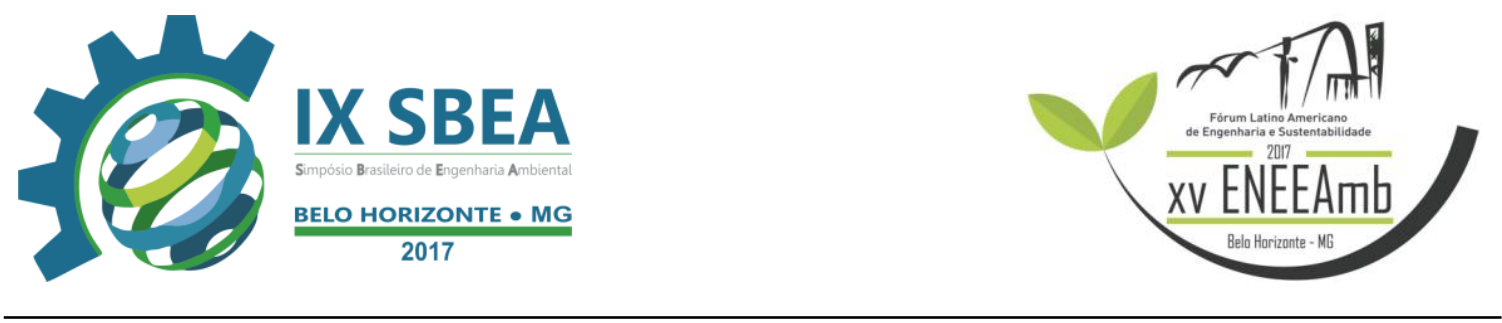

O ponto 05 , em verde (período seco) com classificação de IQA igual a 42,46 (ruim) encontra-se aos fundos de uma fazenda, sendo que para chegar ao ponto de coleta ainda entramos em uma área de mata preservada caminhando cerca de 2 minutos até chegar ao igarapé que se encontra em na parte mais baixa de um terreno em desnível, recebendo lixiviação de todos os resíduos provenientes da infiltração da água da chuva. Os parâmetros com maior diferença entre estes dois pontos foram os sólidos totais dissolvidos e o fosforo total.

No ponto 01, em amarelo (período chuvoso) e no ponto 05 (período chuvoso) já houveram melhoras no IQA, que obteve uma classificação de 65,74 (regular) e 61,76 (regular), respectivamente.

Ainda assim é preocupante o modo como a população local faz uso da água para beber, uma vez que todos relataram durante a parte de triagem que utilizam a água in natura sem fazer uso de nenhuma forma de tratamento.

A secretaria municipal de saúde conta com um agente de saúde dentro do assentamento mas este relatou que há falta de hipoclorito para a distribuição dentro do assentamento e que mesmo quando esta distribuição é feita, muitos não fazem uso.

\section{CONCLUSÕES/RECOMENDAÇÕES}

Ainda têm muita coisa que precisa ser melhorada no saneamento rural do Brasil, áreas como os assentamentos onde as políticas públicas encontram-se defasadas e muitas das vezes nem chegam, acabam por deixar as populações rurais a mercê da própria sorte.

O Projeto de Assentamento São Francisco é mais um destes casos, onde graças à riqueza da biodiversidade amazônica contam com água doce e em condições de suprir a necessidade dos que ali moram.

Os IQA's dos 2 pontos de coleta vieram nos mostrar que a ocupação desordenada e o crescente desmatamento para expansão da produção, seja ela agrícola ou pecuária, levam consequências negativas diretas para a qualidade da água de igarapés como o do Colombo, foco desta pesquisa. 


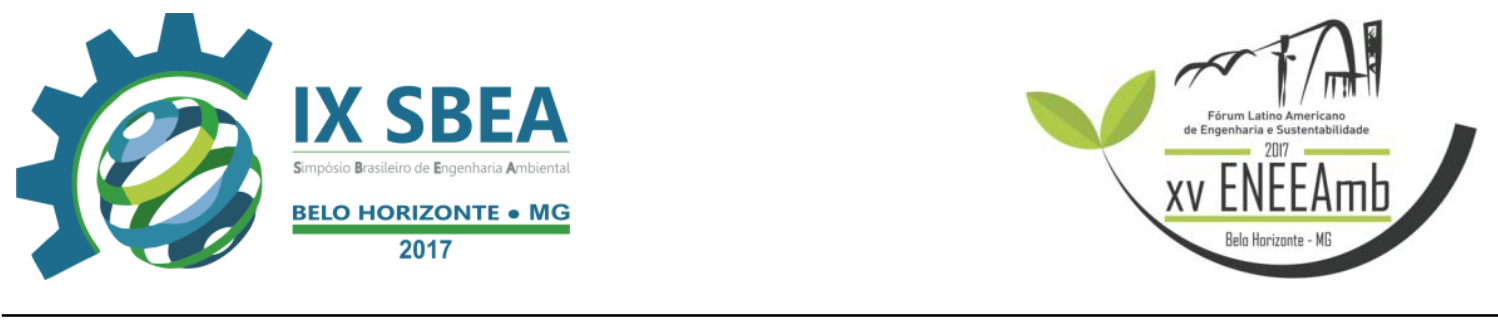

As condições higiênico-sanitárias são de fundamental importância para que aquela população se mantenha com saúde, livre de doenças de veiculação hídrica.

Por isso há a necessidade do acompanhamento do Estado, presente naquele local para fazer com que o suporte chegue aquelas pessoas que ali estão assentadas tenham uma condição de vida digna, conforme prevê a Constituição.

\section{REFERÊNCIAS BIBLIOGRÁFICAS}

AGÊNCIA NACIONAL DE ÁGUAS. Conjuntura dos recursos hídricos no Brasil: informe especial 2012. Brasília, 2012.

Guia nacional de coleta e preservação de amostras: água, sedimento, comunidade aquática e efluentes líquidos. Organizadores: Carlos Jesus Brandão [et al. \}. - São Paulo: CESTESB; Brasília: ANA, 2011.

AMARAL, Luiz Augusto do et al. Água de consumo humano como fator de risco à saúde em propriedades rurais. Rev. Saúde Pública [online]. 2003, vol.37, n.4, pp. 510-514. ISSN 0034-8910.

AMERICAN PUBLIC HEALTH ASSOCIATION - APHA. Standard Methods of the Experimination of Water and Wasterwater. New York: 21ed. 2003. 1085p.

BARCELLOS, Christovam \& QUITERIO, Luiz Antônio Dias. Vigilância ambiental em saúde e sua implantação no Sistema Único de Saúde. Rev. Saúde Pública [online]. 2006, vol.40, n.1, pp. 170-177. ISSN 0034-8910.

BENETTI, A.; BIDONE.F. $\mathrm{O}$ meio ambiente $\mathrm{e}$ os recursos hídricos. In: TUCCI,C.E.M.(Org.). Hidrologia: ciência e aplicação. Porto Alegre: Universidade Federal do Rio Grande do Sul, 2001. p.849-876.

BRASIL. Presidência da República. Lei n ${ }^{\circ}$ 11.445, de 5 de janeiro de 2007. Estabelece diretrizes nacionais para o saneamento básico; altera as Leis $n^{\circ} 6.766$ de 19 de dezembro de 1979, 8.036 de 11 de maio de 1990, 8.666 de 21 de junho de 1993, 8.987 de 13 de fevereiro de 1995; revoga a Lei n 6.528 de 11 de maio de 1978; e dá outras providências. Disponível em: Www.planalto.gov.br/ccivil_03/_ato20072010/2007/lei/11445.html. Acesso em 1 jan. 2016.

Ministério da Saúde. Secretaria de Vigilância em Saúde. Departamento de Vigilância em Saúde Ambienta le Saúde do Trabalhador. Análise de indicadores relacionados à água para consumo humano e doenças de veiculação hídrica no 


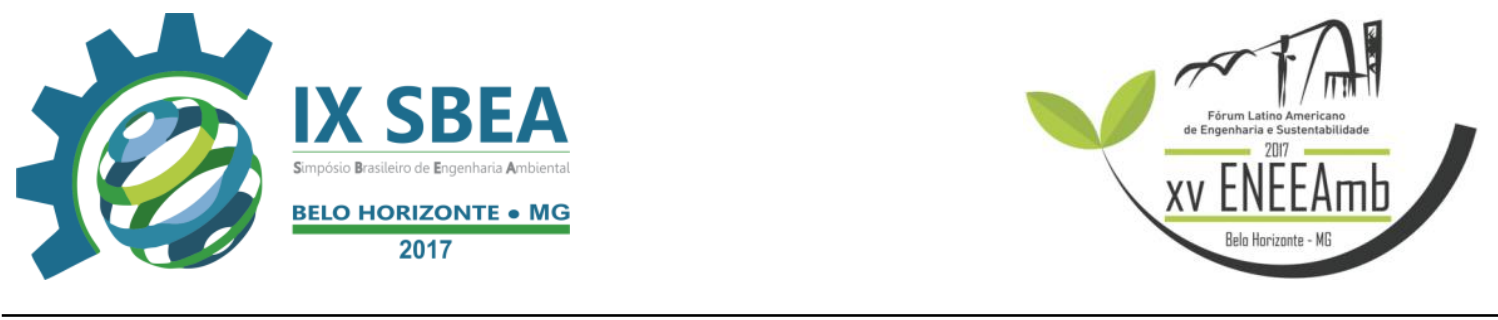

Brasil, ano2013, utilizando a metodologia da matriz de indicadores da Organização Mundial da Saúde / Ministério da Saúde, Secretaria de Vigilância em Saúde, Departamento de Vigilância em Saúde Ambiental e Saúde do Trabalhador. Brasília: Ministério da Saúde, 2015.37 p. : il.Modo de acesso: World Wide Web: <www.saude.gov.br/svs>.ISBN 978-85-334-2234-6.

CESA, Márcia de Vicente; DUARTE, Gerusa Maria. A qualidade do ambiente e as doenças de veiculação hídrica doi: 10.5007/2177-5230.2010v25n49p63. Geosul, Florianópolis, v. 25, n. 49, p. 63-78, jan. 2010. ISSN 2177-5230. Disponível em: <https://periodicos.ufsc.br/index.php/geosul/article/view/15491>. Acesso em: 10 Abr. 2015. doi:http://dx.doi.org/10.5007/2177-5230.2010v25n49p63.

CETESB - Companhia de Tecnologia de Saneamento Ambiental do Estado de São Paulo. Índice de Qualidade das Águas. São Paulo. Disponível em http://www.cetesb.sp.gov.br/userfiles/file/agua/aguas-superficiais/aguas-

interiores/documentos/indices/02.pdf. Acesso em: 04 de abril de 2015.

HOLMES, P.R.,1996. Measuring success in water pollution control; Wat. Res., 34(12): 155-164.

NATIONAL SANITATION FOUNDATION. Water quality index - WQI.NSF, 2006. Disponível em: http://www.nsf.org/consumer/earth_day/wqi.asp\#calculating. Acesso em: 10 abr. 2015.

POSSElT, E. L., COSTA, A. B., LOBO, E. A. Software IQAData 2015. Registro no INPI BR 512015000890-0, Programa de Mestrado em Sistemas e Processos Industriais PPGSPI, Programa de Mestrado em Tecnologia Ambiental (PPGMTA), UNISC, 2015. Disponível em: http://www.unisc.br/ppgspi. Acesso em 03.01.2016

SANTOS, Glauber Eduardo de Oliveira. Cálculo amostral: calculadora on-line. Disponível em: <http://www.calculoamostral.vai.la>. Acesso em: [10.07.2015].

SILVA, G. L.; LUCENA, S. V. O.; AURELIANO, J. T. Proposição de um índice de qualidade de água bruta para abastecimento público. REGA. Revista de Gestão de Águas da América Latina, v.9, p. 17-24, jan/jun. 2012.

VARIS, O.,1996; Water quality models: typologies for environmental impact assessment; Wat. Res.34(12):109-117. 